\title{
Sociologia das profisssões e o profissional da informação
}

\author{
Sociology of professions and the information professional
}

Sociología de las profesiones y el profesional de la información

\author{
Marcia Silveira Kroeff ${ }^{t}$ \\ Miriam de Cassia do Carmo Mascarenhas Mattos ${ }^{2}$ \\ José Claudio Matos ${ }^{3}$ \\ Daniela Fernanda Assis de Oliveira Spudeit ${ }^{4}$
}

\begin{abstract}
Resumo
Ensaio fundamentado por meio de revisão da literatura especializada que relaciona os temas sociologia das profissões e profissional da informação. A pesquisa bibliográfica abrange livros, artigos científicos e trabalhos acadêmicos. Aborda o histórico e a evolução das profissões, as teorias sociológicas, funcionalista e interacionista, bem como a trajetória das profissões, dentre elas a profissão do bibliotecário. Trata das transformações sociais oriundas das tecnologias e as transformações culturais, políticas e sociais que as profissões estão sofrendo em decorrência delas. Por fim, versa sobre as ciências da informação e o fenômeno social da profissão. Conclui que as profissões da informação derivam sua constituição da necessidade de uma jurisdição específica no espaço social para lidar com os documentos e meios de recuperação da informação. De um lado, a configuração mais atual destas profissões fortalece sua identidade e seus laços de compromisso e, de outro, gera subdivisões na tarefa ou na função inicial deste tipo de profissional. A perspectiva acerca da profissão representa uma expectativa sobre a estrutura formativa e um consequente aumento do controle e da vigilância sobre a atuação do profissional individual, resultando em um aspecto positivo e um aspecto negativo. $\mathrm{O}$ positivo é a valorização da comunidade e suas habilidades específicas. O negativo é a mercantilização, o saber específico como um meio de gerar produtividade e riqueza, quando o retorno imediato substitui a busca rigorosa e desinteressada pelo conhecimento que pode gerar demasiada instrumentalização e que impede o avanço de processos mais abrangentes de interação deste grupo profissional com outros.
\end{abstract}

\begin{tabular}{|c|c|}
\hline & Acesse este artigo online \\
\hline \multirow{2}{*}{ 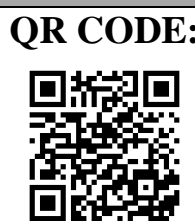 } & $\begin{array}{l}\text { Website: } \\
\text { http://www.revistas.ufg.br/index.php/ci }\end{array}$ \\
\hline & $\begin{array}{l}\text { DOI: } \\
\text { http://dx.doi.org/10.5216/ci.v20i3.41325 }\end{array}$ \\
\hline
\end{tabular}

Palavras-chave: Sociologia das profissões. Profissional da informação. Biblioteconomia.

\footnotetext{
${ }^{1}$ Professora Doutora do Departamento de Biblioteconomia e Gestão da Informação (DBI) do Centro de Ciências Humanas e da Educação (FAED) da Universidade do Estado de Santa Catarina (UDESC). E-mail: marcia.kroeff@udesc.br

2 Professora Mestre e Coordenadora do curso de Biblioteconomia da Unochapecó. E-mail: miriammattos@gmail.com

${ }^{3}$ Professor Doutor do Departamento de Biblioteconomia (DCH) do Centro de Ciências Humanas e da Educação (FAED) da Universidade do Estado de Santa Catarina (UDESC). E-mail: doutortodd@gmail.com

${ }^{4}$ Professora Mestre do Departamento de Biblioteconomia e Gestão da Informação (DBI) do Centro de Ciências Humanas e da Educação (FAED) da Universidade do Estado de Santa Catarina (UDESC). E-mail: danielaspudeit@gmail.com
}

Comun. \& Inf., Goiânia, GO, v. 20, n. 3, p. 18-33, out./dez. 2017 


\begin{abstract}
This essay is based on a specialized literature review relating sociology of professions and information professional. It consists of bibliographic research covering books, scientific articles and academic papers. I discusses the history and evolution of professions, sociological, functionalist and interactionist theories, as well as the trajectory of professions, among them the profession of librarian. It deals with social changes resulting from technologies and cultural, political and social transformations that the professions are experiencing as a result of them. Finally, it discusses information sciences and the social phenomenon of the profession. It concludes that the information professions take their constitution from the need for a specific jurisdiction in the social space, to handle with documents and means of information retrieval. On the one hand, the most up to date configuration of these professions strengthens their identity and their commitment links, and on the other, it generates subdivisions in the initial task or function of this type of professional. The perspective on the profession corresponds to an expectation about the training structure and a consequent increase in the control and surveillance over the activities of the individual professional, resulting in a positive and a negative aspects. The positive aspect is the community's appreciation and their specific skills, and the negative aspect is the merchandization, the specific knowledge as a means of generating productivity and wealth, when the immediate return replaces rigorous and disinterested search for knowledge, which can generate too much instrumentalization, which prevents the advancement of wider processes of interaction of this professional group with others.
\end{abstract}

Keywords: Sociology of professions. Information professional. Library Science.

\title{
Resumen
}

Ensayo basado en una revisión de la literatura especializada que relaciona los temas sociología de las profesiones y profesional de la información. Consiste en investigación bibliográfica que abarca libros, artículos científicos y trabajos académicos. Discute la historia y la evolución de las profesiones, las teorías sociológicas, funcionalista e interaccionista, así como la trayectoria de las profesiones, entre ellas la profesión de bibliotecario. Trata de los cambios sociales resultantes de las tecnologías y las transformaciones culturales, políticas y sociales que las profesiones están sufriendo como consecuencia de ellas. Finalmente, habla de las ciencias de la información y el fenómeno social de la profesión. Llega a la conclusión de que las profesiones de la información derivan su constitución de la necesidad de una jurisdicción específica en el espacio social para lidiar con los documentos y medios de recuperación de la información. Por un lado, la configuración más reciente de estas profesiones fortalece su identidad y sus lazos de compromiso y, por otro, genera subdivisiones en la tarea o la función inicial de este tipo de profesional. La perspectiva sobre la profesión es una expectativa sobre la estructura formativa y un consecuente aumento de control y vigilancia de la actuación del profesional individual, lo que resulta en un aspecto positivo y un aspecto negativo. Lo positivo es la valoración de la comunidad y sus habilidades específicas y el negativo es la mercantilización, el saber específico como medio de generar productividad y riqueza, cuando el retorno inmediato sustituye a la búsqueda rigurosa y desinteresada de conocimiento, que puede generar una demasiada instrumentalización, que impide el avance de los procesos más amplios de la interacción de este grupo profesional con los demás.

Palabras clave: Sociología de las profesiones. Profesional de la información. Biblioteconomía. 


\section{INTRODUÇÃO}

O que é ser bibliotecário hoje?

Esta pergunta sugere uma resposta tão flexível quanto às adaptações que este profissional deve exercer para direcionar o sucesso de sua carreira.

(SILVA, 2005)

s profissões, tal como são conhecidas hoje, têm suas origens em um
processo histórico relacionado às formas de organização do trabalho e às
necessidades sociais. Na medida em que as ocupações produtivas foram se especializando e manifestando identidades cada vez mais delineadas, o conceito de profissão foi gradualmente ganhando forma.

Friedson (1998, p. 51) defende que a profissão se refere a um "[...] amplo estágio de ocupações prestigiosas e muito variadas, cujos membros tiveram uma educação superior e são identificados pelos saberes específicos acessíveis a seu grupo de educação". Abbout (1988, p. 8) define as profissões como "[...] grupos ocupacionais exclusivos que aplicam conhecimentos mais ou menos abstratos a casos particulares, com o objetivo de resolver problemas para uma clientela". Em ambos autores se observa a valorização da relação entre a profissão e o conhecimento, que provém de um processo de formação. Este conhecimento sua posse e sua aplicação - é o elemento mais característico de um determinado profissional. Mais adiante, o aspecto epistêmico ou formativo da profissão será discutido em maior detalhe.

A fim de compreender o surgimento e a evolução das profissões, Dubar (2005) faz referência ao século XI e apresenta a situação em que o mundo do trabalho conciliava as artes liberais e mecânicas, reunindo em uma mesma corporação artesãos e trabalhadores intelectuais. O termo 'profissão' é originário da palavra latina profesione e remete ao ato ou efeito de professar. Tal origem confere a esse termo um sentido de confissão pública, de uma crença, de um sentimento, uma opinião ou modo de ser, conduzindo à concepção de uma atividade ou ocupação especializada que requer preparo e formação (TARGINO, 2000). Este sentido é reforçado pela observação de que as profissões - na sociedade - são indicadores mais ou menos seguros de uma identidade relativamente bem delineada dos indivíduos que aderem a elas.

Segundo Dubar (2005), o termo 'profissão’ é proveniente de juramentos proferidos, ou seja, nascido dos rituais de fé dos juramentos proferidos nas admissões às corporações. Isso significa que ser um 'profissional' implicaria em assumir um compromisso vitalício em relação a uma comunidade ligada por uma atividade produtiva. $\mathrm{O}$ profissional, pelo seu

Comun. \& Inf., Goiânia, GO, v. 20, n. 3, p. 18-33, out./dez. 2017 
juramento - tácito ou expresso -, declara-se adepto de um modo de fazer as coisas, reconhecido pelos membros da comunidade especial em que ingressa e cujos interesses jura proteger. Segundo observa o autor, "oficiais" (dos ofícios) e "profissionais" participam do mesmo modelo de origem: as corporações, isto é, "corpos, confrarias e comunidades". As confrarias surgiram ao fim da economia feudal, no interior delas os membros eram unidos por laços morais e pelo respeito às regulamentações detalhadas de seu status. Havia um compromisso mútuo, assumido pelos profissionais, e que fortalecia em âmbito mais amplo o interesse geral do crescimento econômico e cultural, a diversificação das atividades produtivas e a geração de riqueza.

Com a consolidação das universidades europeias, a partir do século XII, as artes liberais e as artes mecânicas começaram a se dissociar, levando à oposição entre as profissões ensinadas nas universidades "cuja produção cabe mais ao espírito que à mão" e os "ofícios" oriundos das artes mecânicas "em que as mãos trabalham mais que a cabeça". (DUBAR, 2005). Essa divisão nos conhecimentos e processos formativos tem seu efeito na divisão das ocupações e, claro, na divisão das classes sociais. O trabalho do 'espírito' era considerado mais sutil e superior ao trabalho 'manual' e mecânico.

A partir deste breve histórico, o presente estudo objetiva dissertar, com base nas Teorias Sociológicas das Profissões, a ciência da informação enquanto fenômeno social que influencia na atuação dos profissionais da informação.

Essa pesquisa se justifica pelo diálogo que deve ser estabelecido entre as Ciências Sociais e a Ciência da Informação pelo caráter de ciência pós-moderna ${ }^{5}$ e pela reflexão teórico-crítica que deve se estabelecer ao abarcar a atuação dos profissionais da informação na sociedade. Araújo (2003) sinaliza que existe um espaço específico para a discussão da natureza social dos fenômenos informacionais dentro dos programas de pós-graduação. Uma das linhas de pesquisa do Programa de Pós-Graduação em Gestão da Informação da Universidade do Estado de Santa Catarina é Informação, Memória e Sociedade que prevê no seu escopo um diálogo das ciências humanas com as ciências sociais aplicadas. O presente estudo foi um esforço dos professores do Programa de Pós-Graduação, e colegas de profissão, para construir um texto crítico acerca dos temas sociologia das profissões e profissional da

\footnotetext{
${ }^{5}$ Santos (1996) define que essa ciência é entendida como o movimento de superação da crise do paradigma científico dominante desde o século XVII, pela superação do modelo de racionalidade cartesiana, de separação entre objeto e sujeito e busca da ordem. A ciência pós-moderna é interdisciplinar, busca a religação dos saberes abarcado por um pensamento pautado na complexidade.
} 
informação. O texto destina-se a aguçar a reflexão crítica dos alunos do mestrado a respeito do papel e o lugar do profissional da informação na sociedade por meio de discussões levantadas em sala de aula nas disciplinas Fundamentos das Ciências da Informação, Contexto Informacional Contemporâneo e Ética na Gestão da Informação.

Para tanto, o texto constitui-se de um ensaio que relaciona os temas sociologia das profissões e profissional da informação e que se fundamenta em uma revisão da literatura especializada.

A pesquisa bibliográfica realizada abrangeu livros, artigos de revistas científicas, trabalhos acadêmicos e sites governamentais, buscando abarcar publicações relevantes nas duas áreas de saber: sociologia e ciência da informação. O levantamento considerou obras escritas em português, no período de 1980 até 2016. Cabe salientar que somente uma obra fora deste escopo foi incluída no estudo, por sua pertinência, trate-se do artigo de Wilensky $(1974)^{6}$, publicado no American Journal of Sociology. As obras foram localizadas por meio de bases de dados para leitura e análise e obtidas por meio de impressão e empréstimo (livros) na Biblioteca Central da Universidade do Estado de Santa Catarina.

\section{TEORIAS SOCIOLÓGICAS DAS PROFISSÕES}

Com o desenvolvimento das ciências humanas, era de se esperar que um fenômeno de tal importância para a vida social como a profissão recebesse tratamento científico apropriado. Neste caso, com as pesquisas que compõem o campo chamado de "sociologia das profissões". Para Cunha (2006, p. 145), por exemplo, “a sociologia das profissões é um campo complexo e tem produzido várias teorias que tentam explicar o desenvolvimento das mesmas e seu papel na sociedade". O termo "sociologia das profissões" compreende em seu bojo as ideias de emprego (em inglês: job), das profissões liberais (em inglês: profession) e de ofício (em francês: métier). Todo este panorama resulta em implicações e causalidades que merecem ser consideradas em sua complexidade.

$\mathrm{Na}$ sociologia das profissões, existem principalmente duas correntes de pensamento: a funcionalista e a interacionista. É interessante examinar com atenção cada uma delas. Para Rodrigues (2002), a abordagem funcionalista estuda o desenvolvimento das profissões

\footnotetext{
${ }^{6}$ WILENSKY, H. The Profissionalization of everyone? American Journal of Sociology, v.70, n. 1974, p. 137 158. Disponível em:

<http://www.jstor.org/discover/10.2307/2775206?uid=3737664\&uid=2\&uid=4\&sid=21106536746>. Acesso em: 26 abr. 2016.
}

Comun. \& Inf., Goiânia, GO, v. 20, n. 3, p. 18-33, out./dez. 2017 
independentemente das mudanças sociais. Assim, sob a perspectiva funcionalista, a socialização é vista como um processo de manutenção e reprodução da estrutura da sociedade. A abordagem funcionalista privilegia a estrutura social do profissionalismo. Apesar de o conhecimento ser considerado um traço distintivo das profissões, o conteúdo e a natureza do conhecimento profissional não foi objeto nem de análise teórica, nem empírica.

[...] o modelo de profissionalização funcionalista está baseado no modelo liberal de desenvolvimento das profissões dos Estados Unidos e da Inglaterra, onde a intervenção do Estado é mínima e as profissões são consideradas fundamentais para a modernização da sociedade. (PEREIRA; CUNHA, 2007, p. 47).

Em termos epistemológicos, funcionalista é, basicamente, qualquer abordagem nas ciências que explique o seu objeto por meio da função ou resultado específico que ele desempenha. O funcionalismo, tanto em sociologia das profissões como nas demais áreas científicas, tem a vantagem de ultrapassar as definições fixas e abstratas, vindas geralmente da tradição, ao explicar algum fenômeno. Sua abordagem parte de uma consideração do papel, ou função, desempenhado por um órgão, ou entidade complexa, dentro de um sistema de processos que tendem a algum resultado. Pelo seu falibilismo e visão probabilística, o funcionalismo abandona a busca por certezas infalíveis e tem a virtude de um olhar mais experimental sobre seu objeto de estudo.

Rodrigues (2002) afirma que, de acordo com a perspectiva funcionalista, as profissões constituem comunidades cujos membros partilham uma mesma identidade, valores, linguagem e um estatuto adquirido para toda a vida; têm poder de controle sobre si e seus membros, acerca da seleção e admissão de novos membros, bem como sobre a sua formação.

$\mathrm{Na}$ abordagem funcionalista, segundo Diniz (2001, p. 19), uma profissão é "um agrupamento de papéis 'ocupacionais' que se distinguem pela aplicação prática e pela responsabilidade fiduciária do profissional". O profissional é um especialista em virtude do seu domínio da tradição e das habilidades necessárias à aplicação dos seus conhecimentos. Esta concepção é característica do funcionalismo, na medida em que o profissional é aquele que não somente desempenha uma função específica, mas que às vezes pertence a uma comunidade que detém autoridade ou prerrogativa exclusiva do desempenho de tal função ou ocupação.

Por outro lado, as abordagens de Abbout (1988) e Friedson (1998) seguem a linha dos interacionistas, os quais defendem que, para compreender uma profissão, é preciso entender 
sua contribuição para a sociedade. Nesse sentido, os interacionistas analisam a evolução das profissões dentro de um contexto. Para eles, o que caracteriza uma profissão é a sua heterogeneidade, pois os indivíduos compartilham identidades, valores e interesses. As relações que integram o exercício de uma profissão no conjunto complexo de sua situação, frente a estruturas de poder, avanços no conhecimento, na economia e na cultura são elementos a partir dos quais o interacionista procura elaborar o seu estudo.

Por acreditar que a profissão se desenvolve com base nas interações do sujeito com o meio e evoluem a partir de um contexto social, essa pesquisa irá apontar a relação entre a sociologia das profissões e os profissionais da informação com base na teoria sociointeracionista. O interacionismo tem, portanto, a vantagem sobre o funcionalismo de estender o estudo da profissão ao contexto de seu surgimento e às consequências de sua condução como parte dos muitos processos integrados da vida social.

Essa abordagem baseia-se em três pressupostos que definem uma profissão:

- o estatuto profissional resulta do saber científico e prático e do ideal de trabalho, corporizados por comunidades formadas em torno da mesma classe de saber, dos mesmos valores e ética de serviço;

- o reconhecimento social da competência é adquirido por meio de uma formação longa. O conhecimento é a variável central. Para se alcançar o estatuto de profissão, são necessários elevados níveis de conhecimento e dedicação;

- as instituições profissionais respondem às demandas sociais: ocupam uma posição intermediária entre necessidades individuais e sociais. (RODRIGUES, 2002, p. 45).

De acordo Abbout (1988, p. 59), "a principal característica deste sistema é a interdependência entre as profissões que se encontram em permanente disputa por espaço. Cada profissão se dedica a um conjunto de atividades ligadas pelos laços de jurisdição". Na abordagem interacionista, a ênfase é colocada num processo de transformação das ocupações, nas interações e nos conflitos, assim como nos meios e recursos mobilizados nesse processo, chamando a atenção para o papel desempenhado pelas reivindicações e os discursos sobre o saber na transformação de uma ocupação em profissão. (RODRIGUES, 2002). Na perspectiva interacionista, segundo essa autora, as pessoas são sujeitos do processo de socialização, desenvolvendo sua personalidade e apropriando-se dos costumes e valores sociais. É nesse momento que se forma a socialização secundária, ou profissional. $\mathrm{O}$ indivíduo, por meio do convívio, insere-se em vários grupos sociais. A partir da sua inserção em um contexto de 
normas e costumes, previamente estabelecidos, intervém no ambiente, participa desse processo, influencia-o e é influenciado por ele.

Alguns autores como Abbout (1988), Diniz (2001) e Muller (2004) citam Wilensky (1974), em suas obras e segundo eles, o autor apresenta o que chama de "primeiros eventos", que marcam a trajetória das profissões. Em Wilensky (1974) observa-se o estudo histórico de desenvolvimento de 18 ocupações nos Estados Unidos. A partir dessas profissões, Wilensky (1974) descreve o processo de profissionalização, dividindo estas em diversos estágios. Importante ressaltar que tal autor trabalha com profissões fortemente estabelecidas como: Medicina, Direito e Odontologia. A reflexão de Wilensky (1974) parte do exercício de determinado trabalho, em um processo de especialização e fortalecimento de identidades e posições sociais, até o exercer destes de forma exclusiva. A sociedade passa a necessitar dos serviços desempenhados com mais especificidade e técnica, ocorrendo emigração de outras ocupações com menor destaque no mercado.

Do ponto de vista específico da formação, observa-se que a necessidade da dedicação integral à ocupação exerce pressão social - e dos próprios profissionais - para que se estabeleça um espaço qualificado de treinamento e avaliação dos pretendentes ou aprendizes de uma profissão. Vemos surgirem, assim, os cursos universitários. Fora da universidade, esses cursos logo procuram obter status acadêmico e, dentro das academias, constituindo-se em departamentos universitários, o nível de estudo se aprofunda incluindo assuntos mais complexos e aumento da base do conhecimento. Tem-se a elevação da qualidade dos serviços e o nível de compromisso pessoal dos membros do grupo com a área; os cursos universitários proporcionam o surgimento de um corpo docente dedicado ao ensino e ao estudo e o aumento de pesquisas - o corpo de conhecimento da área.

Ocorre, então, a formação de associações profissionais unificando os interesses das instituições de formação e treinamento (universidades) e dos profissionais. Forma-se um novo espaço de organização, com objetivos de fortalecimento da profissão e com diferenciação dos capacitados e não capacitados, subdividindo tarefas mais nobres de outras de menor valor profissional e ampliando a especialização.

Estabelecem-se congregações de professores e novos profissionais e, neste contexto, são possíveis as mudanças de nome da profissão e dos respectivos cursos. As denominações e as condutas tradicionais dão lugar a denominações e práticas regidas pela prática científica e pelos procedimentos formais resultantes do ambiente acadêmico-universitário. Também se pode observar um aumento do rigor, visando excluir do exercício profissional praticantes não 
graduados nos cursos credenciados. Amplia-se o desenvolvimento de novas áreas que ficam mais evidentes e é forte a disputa com profissionais de outras áreas pelo mesmo mercado de trabalho.

Ferramentas institucionais do Estado reconhecem oficialmente as profissões por meio de leis e regulamentações das profissões. São instituídos códigos de ética para estabelecer regras de relacionamento entre pares, eliminar competição interna, impedir a prática pelos não credenciados e garantir a proteção de clientes.

No caso específico das Ciências da Informação, é possível perceber o desenvolvimento de todas essas fases citadas por Wilensky (1974). De acordo com Oliveira (1983), a evolução da profissão de bibliotecário no Brasil ocorreu da seguinte forma:

- criação do primeiro curso de Biblioteconomia em 1911;

- criação de associações profissionais a partir de 1938;

- legislação profissional em 1962 assegurando o monopólio de seus serviços;

- elaboração do Código de Ética da Profissão aprovado em 1963 pela FEBAB;

- elaboração do currículo acadêmico enquadrando a Biblioteconomia em nível de ensino superior em 1962;

- desenvolvimento de corpo de teoria a partir de 1970 com criação de cursos de pós-graduação;

- aumento na produção científica especializada em Biblioteconomia através da publicação de periódicos científicos. (OLIVEIRA, 1983, p. 4).

Friedson (1998, p. 192) entende que uma profissão "representa um tipo de trabalho que as pessoas fazem para ganhar a vida". Sua condição básica é o controle de um conhecimento e habilidades que possuem valor e que se interconectam a outras ocupações e ramos de atuação. Com a sua análise, o referido autor cria a teoria do profissionalismo e consolida o paradigma do poder das profissões:

[...] uma profissão é um tipo de ocupação que se distingue das outras por seu conhecimento e competência especializados, que são necessários para a realização das tarefas numa divisão de trabalho, sendo a profissão um princípio ocupacional de organização do trabalho, sendo importante ter conhecimento especializado, tanto formal quanto abstrato. Esse conhecimento é adquirido por meio da formação especializada, que é dada pelo ensino superior. O monopólio deste conhecimento é uma condição para o acesso ao mercado de trabalho. O controle rigoroso da formação e do exercício profissional é a base do poder das profissões e dos privilégios que são garantidos pelas universidades, pelas associações profissionais e pelo Estado. (FRIEDSON, 1998, p. 192).

Com esta declaração Friedson reconhece que, além de uma ocupação desenvolvida pelo indivíduo para ganhar a vida, a profissão é principalmente uma atividade social, uma 
certa atribuição de autoridade para operar em funções produtivas específicas. Essa autoridade é conferida ao final de um processo de formação e aquisição de conhecimentos específicos. O saber especializado e a formação escolar ou universitária são mencionados pelo autor como componentes da identidade profissional. Em contrapartida a essa formação de que o indivíduo se apropria, a classe ou comunidade profissional exerce sobre ele o controle, de forma a manter a unidade e a qualidade das atividades e dos compromissos envolvidos.

Diniz (2001), por sua vez, faz a análise das profissões sob o ponto de vista de sua constituição, suas formas organizativas e suas estratégias de monopolização de mercado, discutindo questões de supostos processos de "desprofissionalização" e "proletarização", observando a presença de uma dicotomia entre duas teorias no campo das profissões: "a teoria de valorização da profissionalização" e a teoria de crise e "desprofissionalização". Sua visão ressalta a importância de considerar-se a 'cultura' das profissões na estratificação social. A autora conclui que:

Entendida a história das sociedades como uma sucessão de regras de exclusão e de reações à exclusão, o desenvolvimento das profissões constitui apenas uma variante histórica do processo de estratificação social através do monopólio de oportunidades. (DINIZ, 2001, p. 178).

As comunidades profissionais concorrem a fim de elevar o valor de suas atividades específicas, ao mesmo tempo em que as relações econômicas, representadas pela figura dos empregadores e dos clientes, têm o interesse de oferecer menos em troca dos mesmos serviços. Dessa tensão, o efeito no mundo do trabalho, é que surge o que Diniz chama de 'estratificação social'. Já Mueller (2004) afirma que autores mais recentes têm adotado perspectiva baseada em concepções macro-históricas para estudar as profissões e argumentam que a influência das condições sociais em que ocorrem os processos de profissionalização são determinantes para entender o fenômeno da profissão como um todo, e não apenas as características inerentes às ocupações, mencionadas pelos funcionalistas.

As profissões vêm sofrendo transformações culturais, políticas e sociais na realidade atual, levando ao questionamento quanto a seus métodos e suas relações de trabalho, modificando o conhecimento e o fazer humanos.

A tecnologia é uma das causas que impulsiona as mudanças, levando ao constante questionamento e resultando em novos arranjos na condição social das profissões. Tais mudanças fazem com que sejam necessárias, na atualidade, novas formas de atuação na sociedade, sendo que uma das tendências apresentadas é um reconhecimento de novos limites 
à autoridade dos profissionais e um reordenamento das relações interprofissionais no contexto de uma nova divisão de trabalho, "nesse sentido, tudo indica que os grupos profissionais continuarão sobrevivendo, apesar das mudanças" (CUNHA, 2006, p. 149). Naturalmente pode haver alterações de configuração, mas a dinâmica que mobiliza os grupos profissionais parece ser basicamente a mesma que vem sendo revelada pela abordagem interacionista aqui apresentada.

Abbout (1988) apud Mueller (2004, p. 27) aborda que cada profissão se dedica a um conjunto de tarefas às quais está ligada pelo que chama de "laços da jurisdição". A jurisdição é um conceito central na teoria de Abbout (1988, p. 59) e "se refere ao direito à exclusividade da prática profissional por um determinado grupo profissional”. Abbout entende que as profissões são sistemas interdependentes com uma estrutura interna própria, que lutam entre si pela manutenção da exclusividade de seus espaços de atuação, como também disputam novos espaços. Assim, o modelo interacionista de Abbout sistematiza a forma como as profissões se integram e interagem em um sistema interdependente e dinâmico. A resistência ou fragilidade desses laços é consequência da prática diária do trabalho profissional, não sendo absoluta e nem permanente. As profissões interagem como em um sistema ecológico, no qual o que ocorre a um elemento, afeta a todos.

Para Abbout (1988), cada profissão evolui de forma diferente e está em constante crescimento, sofrendo influências do meio. Esse autor considera que as profissões fazem parte de um sistema e são interdependentes. Cada profissão mantém o domínio e o controle de uma "jurisdição" dedicando-se a um conjunto de tarefas. A resistência ou a fragilidade dos laços juridicionais são consequências da prática profissional. As profissões estão em permanente disputa pelo domínio de uma jurisdição específica para garantir seu espaço de trabalho. Abbout (1988) estuda as profissões por meio de sua evolução e de suas relações, enfatizando as disputas por áreas de trabalho, em que cada uma delas influencia e é influenciada pelas outras.

Segundo Abbout (1998, p. 59) “campos de determinado domínio ocupacional frequentemente são disputados por novos ocupantes ou concorrentes". Outra forma de compreender o conceito cunhado por Abbott de jurisdições é dizer que tal termo se refere ao direito à exclusividade da prática profissional por um determinado profissional. Segundo sua teoria, forças internas como desenvolvimento de novos conhecimentos e reconfiguração de uma estrutura profissional; e forças externas como mudanças de legislação, mudanças 
culturais e surgimento de novas tecnologias, podem trazer abalos a uma profissão, modificando sua jurisdição ou seus modos de conduta profissional.

\section{A CIÊNCIA DA INFORMAÇÃO E O FENÔMENO SOCIAL DA PROFISSÃO}

Tendo como referência o modelo de Abbott e Mueller (2004), levanta-se algumas questões sobre a emergência e evolução dos profissionais da informação no Brasil. A Classificação Brasileira de Ocupações (BRASIL, 2003) esclarece que bibliotecários, documentalistas e analistas de informação formam o grupo de profissionais da informação no código 2612. Mueller (2004) adota o pressuposto de que os profissionais da informação detêm hoje o domínio do que se convencionou chamar, de maneira ampla e imprecisa, "jurisdição da informação". A intenção da autora foi de compreender o momento atual e suas raízes, além de prever o futuro por meio de relato de acontecimentos da história dos grupos (bibliotecários, arquivistas e cientistas da informação), como meio de identificar fatos relevantes para a aplicação do modelo teórico escolhido por ela para explicar tais ocorrências.

De acordo com Mueller (2004), há um consenso de que certas características mínimas são comuns a todos os chamados profissionais da informação, o que permite o uso da designação em diversos contextos, mas o entendimento parece depender de quem usa o termo e da audiência para a qual se dirige. Em geral, na literatura voltada à Ciência da Informação parece haver consenso de que se incluem entre os profissionais da informação os bibliotecários, os arquivistas, mestres e doutores formados nos programas de Pós-Graduação em Ciência da Informação.

O uso dos termos "profissões da informação" e "profissionais da informação" se tornou usual nas últimas décadas na literatura especializada, refletindo a compreensão de que, na realidade atual, os serviços de informação apresentam complexidade, demandando mais que o trabalho isolado de qualquer profissão. Além disso, há certo consenso acerca da especificidade dos ofícios desempenhados por esta comunidade profissional, de forma que o trabalho por ela desenvolvido é especializado, e não convém que seja atribuído a leigos.

$\mathrm{Na}$ literatura da área de Ciência da Informação observa-se a crescente ampliação do escopo de habilidades e adaptações necessárias para que os profissionais da informação atendam de forma satisfatória aos usuários e tenham sucesso em sua carreira no mercado de trabalho. Nesta perspectiva, os profissionais da informação vêm acompanhando e buscando 
alternativas para sua atuação frente ao avanço e popularização da tecnologia e sua influência junto aos beneficiários do seu trabalho.

Cianconi (1991, p. 206) entende que "já não se pode pensar nas profissões de forma corporativista, arraigada a modelos antigos e excludentes", pois as habilidades profissionais exigidas transcendem as técnicas tradicionais consideradas isoladamente. Assim, para atingir os objetivos organizacionais deve-se ter em mente que a informação é um recurso estratégico que deve ser gerenciado, uma vez que a gestão informacional é uma atividade vital para qualquer organização da sociedade nos diversos setores. Do ponto de vista organizacional, a eficácia da informação depende, em grande parte, da forma com que ela é administrada e "[...] do bom entendimento de certos conceitos e relações” (FREITAS; KLADIS, 1995, p. 1).

O surgimento de novas técnicas de produção, circulação e transmissão de informações implica diretamente nos profissionais da informação, não apenas como uma adaptação às novas mecânicas e ferramentas, mas como um novo modo de pensar e agir.

Um fator a ser considerado é a ampliação do campo de atuação, em que as demandas nascentes vão exigindo a constante especialização, que resulta em perfis de formação e trajetórias diversificadas, no que antes era atribuído a um perfil e uma trajetória mais uniforme e genérica.

Sabidamente, uma das principais atividades da área de Ciência da Informação é a organização ou recuperação da informação. Nesse sentido, verifica-se uma crescente busca no desenvolvimento dos estudos teóricos e metodológicos que venham a contribuir nas atividades de análise, síntese, representação e recuperação do conteúdo informacional, contribuindo tanto para a sedimentação teórica da área, quanto para a formação do profissional que nela atua (EUCLIDES, 2007). Esses debates fazem parte da formação profissional na graduação e/ou pós-graduação, sendo explorados também por meio da atuação profissional e cursos de outra natureza, que constituem a formação continuada.

A chamada "era da informação" pode ser entendida como a emergência e o fortalecimento de diversos ramos ocupacionais, cuja função e relevância ultrapassam os aspectos físicos do trabalho e da produção de valor. Consequentemente, tal fenômeno se caracteriza pelo envolvimento dos indivíduos com atividades baseadas na capacidade intelectual, o que pressupõe o manuseio de informações. Isto equivale a supor que há cada vez mais inteligência corporificada nos artefatos - sobretudo na tecnologia da informação e comunicação - e que em resposta a este acúmulo de inteligência no mundo cultural, os 
indivíduos precisam se adaptar, fazendo um uso correspondente de sua inteligência individual.

O crescimento da complexidade da sociedade, e inevitavelmente das organizações, é reflexo direto do entendimento da informação como recurso estratégico. E ainda mais: esta expansão da geração, fluxo e emprego da informação parece ser um processo irreversível, uma vez que a manipulação cotidiana de enormes montantes de informações nas mentes, nos computadores e na cultura humana em geral, produz exponencialmente ainda mais informação.

Neste moderno cenário, as atividades informacionais firmam uma nova concepção ${ }^{7}$ no campo profissional, cuja valorização da informação como bem econômico advêm, sobretudo, da mudança paradigmática na qual a ênfase respalda-se: a) na visão holística dos fenômenos e recursos informacionais; b) na atuação profissional calcada na multidisciplinaridade e multiprofissionalismo; c) na aplicação das novas tecnologias; d) no entendimento de que a segregação e a inércia profissional são resultados das atitudes dos próprios profissionais.

\section{CONSIDERAÇÕES FINAIS}

As profissões da informação derivam sua constituição da necessidade de uma jurisdição específica no espaço social para lidar com os documentos e meios de recuperação da informação. De um lado, a configuração mais atual destas profissões fortalece sua identidade e seus laços de compromisso e, de outro, gera subdivisões na tarefa ou função inicial deste tipo de profissional. A grande causa disso se atribui ao avanço tecnológico. A dita "explosão" informacional exige uma profissão, ou um complexo de profissões, para organizar, disponibilizar e selecionar informações. Afinal, com essa interação, outros profissionais de diversos campos de atuação podem se desobrigar de um conjunto de tarefas que, por sua complexidade, exigem habilidades e tempo específico para serem executadas com eficiência.

O fenômeno social da formação e do empoderamento da comunidade constituída em torno das profissões da informação é, portanto, inerente a um mundo em que o valor das atividades se desliga gradativamente das operações mecânicas e materiais, em direção a um

\footnotetext{
${ }^{7}$ Vale registrar que atualmente tem-se aumentado a possibilidade dos indivíduos controlarem e modelarem suas vidas na concepção de informação como recurso estratégico.
} 
legado cultural que nutre a si mesmo e que possui suas próprias regularidades. Esta configuração ultrapassa a divisão dualista, entre profissões do "espírito" e das "mãos". A organização contemporânea parece ser mais polimórfica e tem seu eixo na informação e em seu manejo. Em resposta a esta demanda, a formação científica e universitária recebe o encargo de produzir as novas gerações de integrantes desta categoria profissional. A perspectiva acerca da profissão, portanto, representa uma expectativa sobre a estrutura formativa e um consequente aumento do controle e da vigilância sobre a atuação do profissional individual por parte das entidades representativas da classe.

Isto tem um aspecto positivo e um aspecto negativo: o positivo é a valorização da comunidade e suas habilidades específicas. O fortalecimento, portanto, da identidade e dos laços de ligação da profissão com as outras comunidades. Uma consequência disso é o aumento do conhecimento específico da profissão e sua rigorosa transmissão aos novos membros do seu grupo. $\mathrm{O}$ aspecto negativo é a mercantilização: o saber específico é visto de fora como um meio de gerar produtividade e riqueza, e, assim, o retorno imediato substitui a busca rigorosa e desinteressada pelo conhecimento. Isto pode ter como consequência uma demasiada instrumentalização, o que impediria o avanço de processos mais abrangentes de interação deste grupo profissional com outros.

\section{REFERÊNCIAS}

ABBOUT, A. The System of professions: na essay on the division of expert labour. Chicago: The University of Chicago Press, 1988.

ARAÚJO, Carlos Alberto Ávila. A ciência da informação como ciência social. Ciência da Informação, Brasília, v. 32, n. 3, p. 21-27, set./dez. 2003.

BRASIL. Ministério do Trabalho e Emprego. Classificação brasileira de ocupações: CBO 2002. Brasília: MTE, 2003. Disponível em: 〈http://www.mte.gov.br〉. Acesso em: 26 abr. 2017.

CIANCONI, R. B. Gerência da informação: mudanças nos perfis profissionais. Ciência da Informação, Brasília, v. 20, n. 2, p. 204-208, jul./dez. 1991.

CUNHA, M. V. da. As profissões e as suas transformações na sociedade. In: CUNHA, M. V. da; SOUZA, F. das C. de. (Org.). Comunicação, gestão e profissão: abordagens para o estudo da Ciência da Informação. Belo Horizonte: Autêntica, 2006.

DINIZ, M. Os donos do saber: profissões e monopólios profissionais. Rio de Janeiro: Revan, 2001. 
DUBAR, C. Das profissões à socialização profissional. In: DUBAR, C. A socialização: construção das identidades sociais e profissionais. São Paulo: Martins Fontes, 2005.

Profissões, organizações e relações profissionais. In: DUBAR, C. A socialização:

construção das identidades sociais e profissionais. São Paulo: Martins Fontes, 2005.

EUCLIDES, M. L. Representação das necessidades de informação na organização da informação: uma análise de modelos teóricos de busca. 2007. 111 f. Dissertação (Mestrado) Universidade Estadual Paulista, Faculdade de Filosofia e Ciências de Marília, 2007.

FREITAS. H.; KLADIS. C. M. Da informação à política informacional das organizações: um quadro conceitual. RAP., São Paulo, v. 29, n. 3, p.73-86, jun/set. 1995.

FRIEDSON. E. As profissões são necessárias. In: FRIEDSON. E. O renascimento do profissionalismo: teoria, profecia e política. São Paulo: Edusp, Coleção Clássicos, n. 12, 1998.

MUELLER. Uma profissão em evolução: profissionais da informação sob a ótica de Abbott. Brasília, UNB: repositório institucional, 2004. Disponível em:< http://repositorio.bce.unb.br/bitstream/10482/1438/1/CAPITULO_ProfissaoEvolucao.pdf>. Acesso em: 1 abr. 2017.

OLIVEIRA, Z. C. P. de. O bibliotecário e sua autoimagem. São Paulo: Pioneira, 1983.

PEREIRA, E. A. J.; CUNHA, M. V. da. Reflexões sobre as profissões. Enc. Bibli.: R. Eletr. Bibliotecon. Ci. Inf., Florianópolis, n. 24, p. 44-58, 2007.

RODRIGUES, M. L. Sociologia das Profissões. Oeiras: Celta, 2002.

SANTOS, Boaventura de Sousa. Um discurso sobre as ciências. 8. ed. Porto: Afrontamento, 1996.

SILVA, F. C. C. Bibliotecários especialistas: guia de especialidades e recursos informacionais. Brasília: Thesaurus, 2005.

TARGINO, M. G. Quem é o profissional da informação? Transinformação, Campinas, v. 12, n. 2, p. 61-69, jul./dez. 2000.

WILENSKY, H. The Profissionalization of everyone? American Journal of Sociology v. 70, p. 137-158, 1974. Disponível em:

<http://www.jstor.org/discover/10.2307/2775206?uid=3737664\&uid=2\&uid=4\&sid=2110653 6746>. Acesso em: 26 abr. 2017. 